\title{
Mechanized arc welding of relit-cupronickel composite material
}

\author{
Firas Al Quran ${ }^{l, *}$, Mohamed Matarneh ${ }^{l}, V . V$. Chigarev ${ }^{2}$ and A.G. Belik ${ }^{2}$ \\ ${ }^{1}$ Al-Balqa Applied University1, Al-Huson University College, Department of Mechanical \\ Engineering P.O. Box 50, Al-Huson-Irbid, Jordan \\ ${ }^{2}$ Priazovsky State Technical University, Department of Mechanical Engineering, 7 Universitetska str., \\ Mariupol, Donetsk reg., 87500, Ukraine
}

\begin{abstract}
Powder-coated tape electrodes (powder-coated tapes) are used for doped and composite alloys welding. Using powder-coated tape for welding of wear-resistant alloys is stipulated by a number of factors in comparison with using electrodes for manual arc welding, flux cored wires, sintered tapes etc. The main task of mechanized arc welding of composite materials is to keep the wear-resistant particles in their initial condition and to ensure the weld metal receives them in the quantity demanded.
\end{abstract}

\section{Introduction}

The cover of powder-coated tape is square. The cover can consist of one metal tape or two metal tapes of the same or different chemical composition, while the cover metal tapes parts may be of different thickness. Powder-coated tape is produced by a rolling method that allows introducing to the core powder components of the size of a particle close to the depth of a shaped metal covering tape [1-3].

An important processing characteristic feature of powdered electrodes is a space factor $\left(\mathrm{K}_{\mathrm{s}}\right)$ which is determined as a core mass $\left(\mathrm{M}_{\mathrm{c}}\right)$ - to - powdered electrode mass $\left(\mathrm{M}_{\mathrm{el}}\right)$ ratio [4].

$$
K_{s}=\frac{M_{e l .}-M_{c}}{M_{e l}} * 100 \%
$$

Where $\mathrm{M}_{\mathrm{c}}$ is powdered electrode cover mass.

In powder-coated tapes the space factor value is higher than in other powder-coated electrode materials and it can be controlled with different processing methods, that gives the possibility to receive high values [5].

The powder-coated tapes with higher space factor values make it possible to introduce more alloying components to the core composition and to get a required chemical composition in the build-up layer. This is highly important while designing and producing powder-coated tape for mechanized arc welding of composite materials. A distinctive feature of structurally inhomogeneous alloying or composite materials is that a strengthening phase in the form of wear-resistant high-melting particles is introduced into

* Corresponding author: firasmfsjordan3@yahoo.com 
the melt in its initial state. During mechanized arc welding the wear-resistant particles do not lose their properties, form and dimensions and during the weld pool melt crystallization we get a build-up layer with wear-resistant particles sintered with a binder metal. Thereby we get a build-up layer which has specified service properties. The composite material structure is shown at fig. 1 .

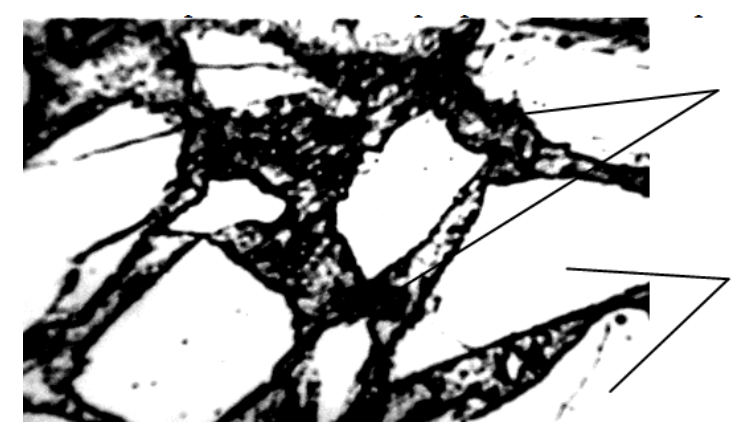

\section{binder metal of} cupronickel

Reinforcing particles in the form of tungsten carbide

Fig. 1. Composite material structure

While doped alloy welding, the strengthening phase: carbides, borides, silicides and other wear-resistant particles is produced from the weld pool melt due to alloying elements interaction. The microstructure of wear-resistant doped alloy can be seen at figure 2 .

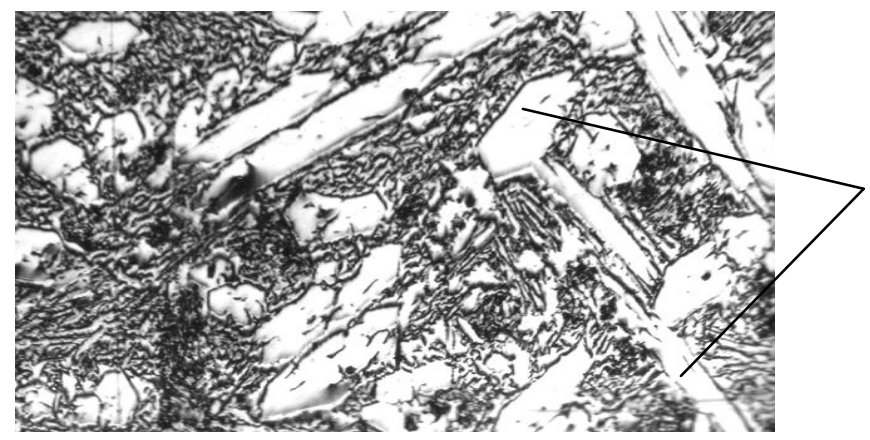

Reinforcing particles in the form of chromium carbides

Fig. 2. Microstructure of "Sormait" alloy built-up with powder-coated tape

The main task of mechanized arc welding of composite materials is to keep the wearresistant particles in their initial condition and to ensure the weld metal receives them in the quantity demanded. It is possible to determine the volume content of wear-resistant particles of any kind using the bulk weight - to - density of wear-resistant particles material ratio.

$$
\mathrm{W}=\frac{\mathrm{a}}{\mathrm{j}}
$$

where $\mathrm{W}$ is volume concentration of wear-resistant particles in the build-up metal, \%; a is bulk weight of wear-resistant particles, $\mathrm{g} / \mathrm{sm} 3$;

$\mathrm{j}$ is density of wear-resistant particles material, $\mathrm{g} / \mathrm{sm} 3$.

The amount of binder metal, under the condition that the obtained quantity of wear-resistant particles is fully bound (sintered) with this binder metal, can be determined in the following way:

$$
\mathrm{M}_{\mathrm{c}}=1-\frac{\mathrm{a}}{\mathrm{j}}
$$


Where Mc is the amount of binder metal in the composite material.

Having these design values it is possible to determine the powder-coated tape composition and its space factor, the binder metal composition for composite material welding. To choose a binder metal for composite material it is necessary to meet the following requirements: the binder metal should not interact with wear-resistant particles; the binder metal should have good wettability and keep wear-resistant particles in the buildup layer; the binder metal should have a good strength the binder metal should correspond the sanitary standards with its harmful emissions to the environment.

\subsection{Peculiarities of composite materials forming}

The composition of tungsten carbides (relit - mechanical mixture of carbides $\mathrm{WC}+\mathrm{W} 2 \mathrm{C}$ ) and binder metal of cupronickel, chromium carbides and nickel-base binder metal meet these requirements to a high degree [6-8]. The microstructure of these composites is shown at figures 3 and 4 .

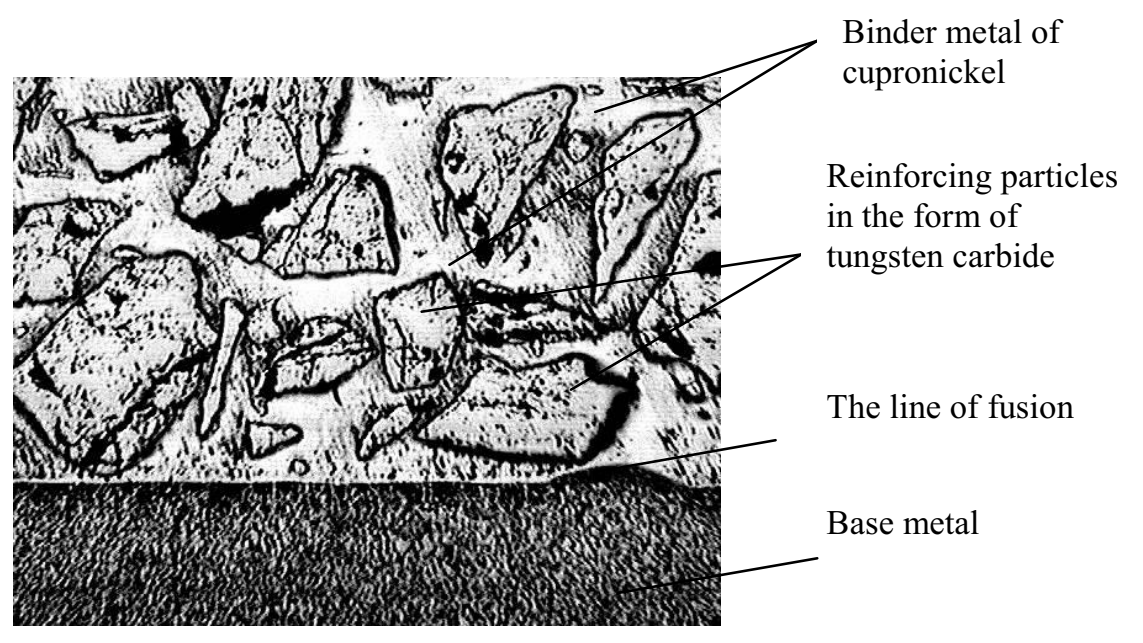

Fig. 3. Microstructure of relit-cupronickel composite material ( $\mathrm{Cr} 50)$

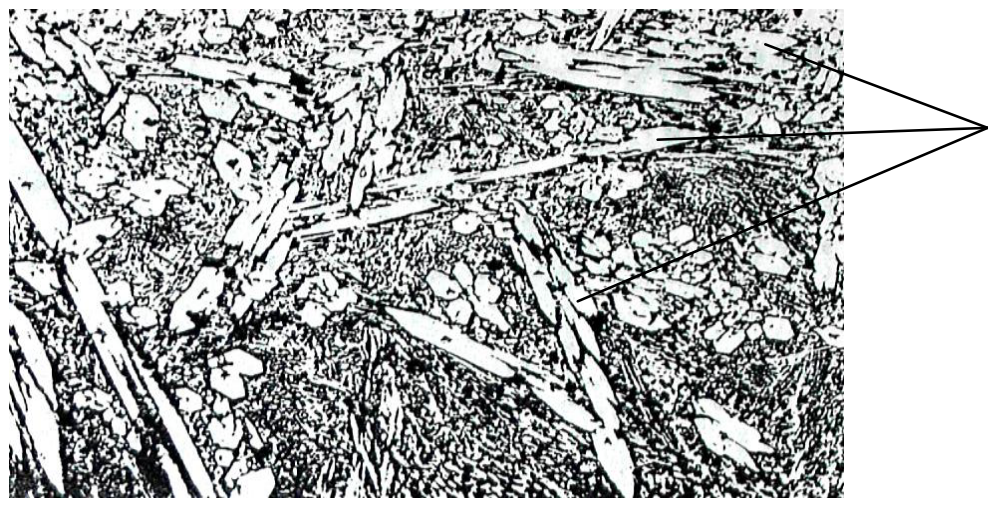

Reinforcing particles in the form of chromium carbide

Fig. 4. Microstructure of chromium-nickel composite material ( $\mathrm{Cr} 50)$

Composite materials' binder metals strength properties are of minor importance as, depending on the kind of wear, composite materials' general wear basically depends on the 
strength properties of the wear-resistant particles. As a rule, at the beginning of abrasion and gasoabrasive wear we can observe a heavy wear of binder metal until the abrasive particle contacts wear-resistant particles. Then the binder metal seems to be in a sort of a shade of the wear-resistant particles that leads to the so-called "shaded effect". In this case the wear-resistant particles are not destroyed and firmly adhered due to the binder metal [9].

\subsection{Experimental program}

Materials and Sample Preparation

While producing the powdered-coated tape crushed particles of a splinter and spherical form are used as wear-resistant particles. The crushed particles have different form; they are the result of the tungsten carbide bar mechanical fragmentation due to which the tungsten carbide particles have different size, form and even may have fractures, cracks that reduce their strength properties. In the industry one produces grain cast tungsten carbide "3" of different fractions which size varies from 0.18 till $2.5 \mathrm{~mm}$ and with the grain equiaxed quality degree equal to 1.45 . The cast tungsten carbide fractures are shown at figure 5 .

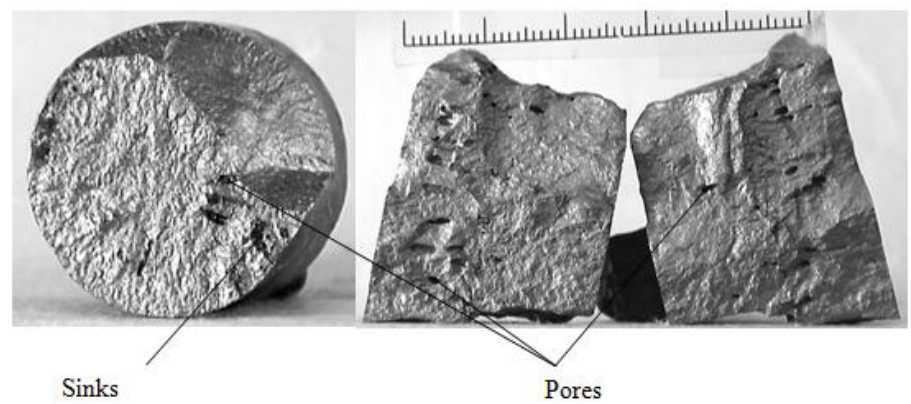

Fig. 5. Cast tungsten carbide fractures

The cast tungsten carbides in the form of spherical grains with the high degree of solidity and strength, and such qualities as flowability, uniformity, and without such defects as tears and cracks are also applied [10]. The cast tungsten carbide spherical (globular) particles of a different size are obtained by thermal centrifugal sputtering cast cylindrical bars with its diameter of $29-30 \mathrm{~mm}$ and its length of $240-250 \mathrm{~mm}$. The sputtering is realized at a high rate of blank parts rotation, 4000 - 10000 revolutions per minute, due to which spherical particles of a different size can be obtained. A special plant was designed for this process [11]. The cast tungsten carbides of a spherical and splinter form are shown at figure 6.

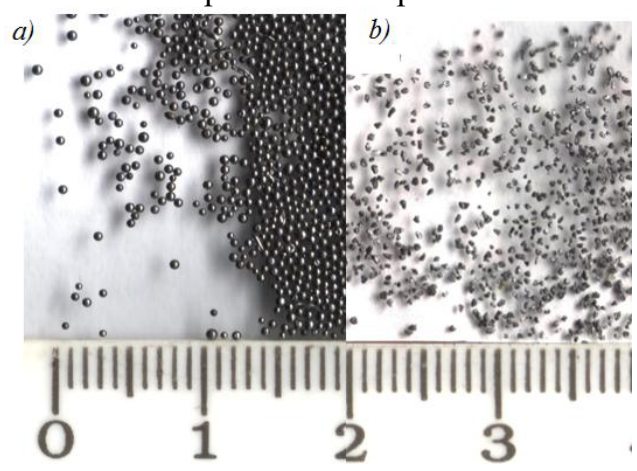

Fig. 6. Cast tungsten carbide of a spherical (A) and splinter (B) form. 
In accordance with the analysis of strength properties of cast tungsten carbide particles of a spherical (globular) and splinter form, the spherical form has the advantage. The crushing load for spherical particles of tungsten carbides will be $20,2 \mathrm{~kg}$, while for splinter particles it is $8,2 \mathrm{~kg}$. With the multiple crushing load the cast tungsten carbide particles of a spherical form got crushed after 200-400 cycles while the splinter particles got crushed after 20-60 cycles. The analysis results are shown at figure $7[10]$.

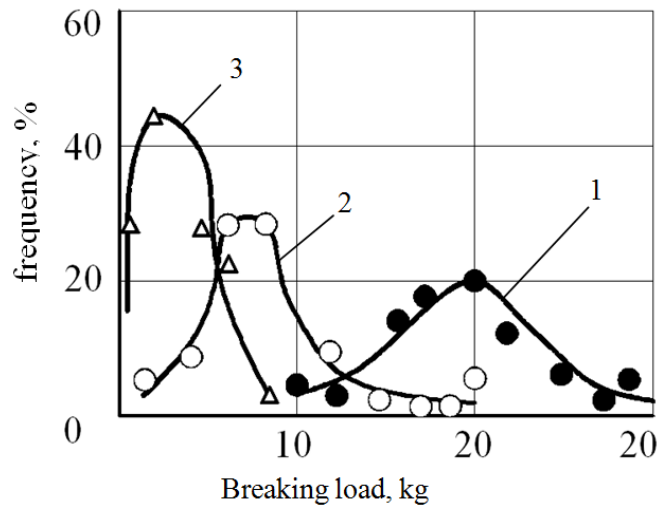

Fig. 7. Strength characteristics of particles with the size of $0,4-0,6 \mathrm{~mm}$ : 1- spherical cast tungsten carbide particles; 2 - crushed cast tungsten carbide particles; 3 - ferrochromium particles (to compare)

Such kind of strength nature is confirmed by cast tungsten carbide particles microstructure formation. By centrifugal sputtering cast tungsten carbides have a compact fine-grained structure [12].

\subsection{Results and discussion}

By mechanized composite arc welding with cast tungsten carbides in a strengthening phase the built-up layer gets formed with uneven particles distribution. The cast tungsten carbides, possessing high density characteristics, get located near the weld line with the binder metal above them, picture 4. Therefore it is necessary to take this moment into consideration while electrode material designing to have enough quantity of the binder metal to sinter wear-resistant particles (carbides) without excess. The build-up samples can be seen at figure 8 .

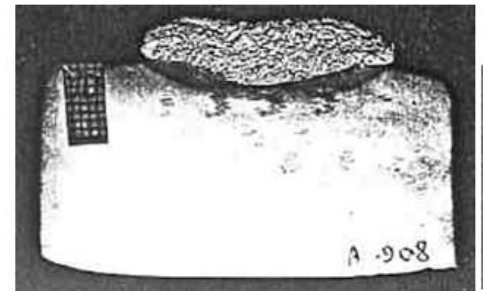

a

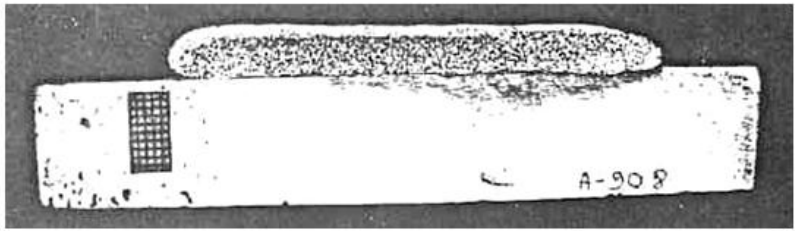

$\mathrm{b}$

Fig. 8. Build-up composite material formation: a - single-layer welding; $b$ - broad-layer welding

With furnace composite welding method, when the strengthening phase (carbides) is formed in a certain volume, in the space between the well-fixed fixture and the surface of the element that requires strengthening, and the binder metal is spread through the formed channels between the particles, the composite structure forming goes evenly. The composite formation by the furnace welding method is shown at figure 9 . 


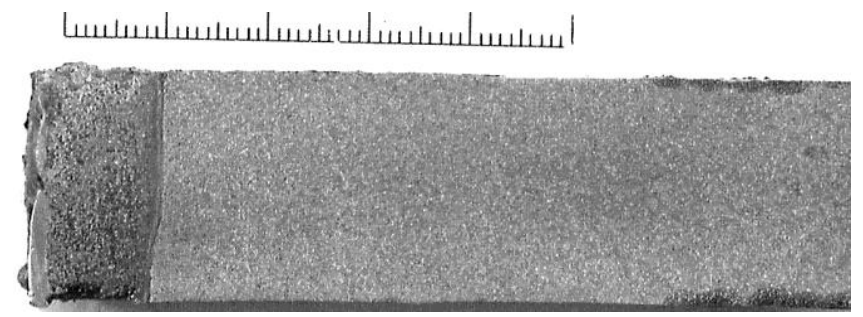

Fig. 9. Sample built-up by the furnace welding method

\section{Conclusions}

According to the examined microstructures, the furnace welding method makes the carbides be distributed in an even way, the binder metal only sinters these particles along the full surface and volume.

The way of choosing the welding method, the form of wear-resistant particles and their quantity depends on the service conditions of the item and the wear mode.

\section{References}

1. Pat. 3999036 USA. Powder-cored strip electrode for surfacing with abrasion-resistant composite alloys /V.A. Muratov, V.V. Chigarev, L.S. Malinov etc. - 1975.

2. Pat. 7512641 France. Ruban-electrode a ame en poundre pour le chargement avec des pseudoalliages resistant a Jusure / V.A. Muratov, V.V. Chigarev, L.S. Malinov etc. -1977.

3. Valeriy V. Proizvodstvo i primenenie poroshkovih lent dlia naplavki iznosostoikih splavov (Powder-coated tape producing and applying for wear-resistant alloys welding) / V.V. Chigarev // Machine welding. - 1994. - №2. - P. 51-52.

4. Valeriy V., Vibor optimalnih parametrov poroshkovoi lenti (Powder-coated tape optimal parameters choosing) / V.V. Chigarev, O.V. Yakimenko, P.F. Lavrik // Welding engineering, 1980. - №9. - P. 19-21.

5. Valeriy V., Sposobi povishenia koeffitsienta zapolnenia (Ways of space factor increasing) / V.V. Chigarev, A.G. Belik, Yu.V. Sergienko // Herald of Donbass State Machine Building Academy. Collection of science papers. - 2006. - №2(4). - P. 13-16.

6. B.E. Paton Novie sposobi izgotovlenia bimetallicheskih izdeliy namorazhivaniem i zalivkoi zhidkogo prisadochnogo splava (New methods of bimetal elements production by freezing-out and filling liquid process alloy) / B.E. Paton, D.A. Dudko, B.I. Maksimovitch and others // Machine welding. - 1969. - № 6. - P. 41-46.

7. A.N. Kabanets $\mathrm{Ob}$ istochnikah vodoroda $\mathrm{v}$ svarochnoi vane pri naplavke antifriktsionnikh aluminievih splavov (About hydrogen sources in the weld pool by antifriction aluminum alloy welding) / A.N. Kabanets, V.Ya. Zusin // Welding engineering. - 1984. - №11. - P. 41-42.

8. Yu.A. Yuzvenko Osobennosti gazoobrazivnogo iznosa kompozitsionnih splavov (Composite gasoabrasive wear singularity) / Yu.A. Yuzvenko, A.P. Zhudra, E.I. Frumin and others // Machine welding.- 1972.- №8. - P. 35-38.

9. Mohammad A. Application of flux-cored strips for ruggedization and reconditioning of machine parts / Mohammad Ahmad, W.W. Chigarev, A.G. Belik // Modern Developments in Renewable Energy and Sustainabiliti, Kuala Lumpur, Malaysia, 2008. - P. 110-118.

10. Yu.A. Yuzvenko Novie puti poluchenia dugovoi naplavkoi kompozitsionnih sloev osobo visokoi iznosostoikosti (New ways of forming composite layers of high wear resistance by arc welding) / Yu.A. Yuzvenko, E.I. Frumin, M.A. Paschenko and otheres // Machine welding. 1975. - №1. - P. 49-52. 
11. A.c. №1381840 USSR. Ustanovka tsentrobezhnogo raspilenia sterzhney iz tugoplavkih materialov (Centrifugal sputterer of refractory metal bars) / A.I. Beliy and otheres - Appl. 10.07.86; Published 15.11.87.

12. V.I. Dzikovich Vliyanie protsessa termotsentrobezhnogo raspilenia na svoistva sfericheskih chastits karbidov volframa (Influence of thermal centrifugal sputtering process on the form of spherical cast tungsten carbide particles) / V.I. Dzikovich // Machine welding. - 2009. - №4. P. 52-54. 